\title{
ABSTRACT
}

The Integration of Surface Micromachined Devices with Optoelectronics:

\section{Technology and Applications}

$$
\text { CONF- } 980720-
$$

M.E. Warren, O. Blum, C.T. Sullivan, R.J. Shul, M.S. Rodgers and J.J. Sniegowski

Sandia National Laboratories, MS0603, Albuquerque, NM 87185

We describe progress at Sandia National Laboratories in integrating MEMS and optoelectronics. We present processes developed for hybrid integration of the technologies and demonstrations of microoptomechanical systems. 


\section{DISCLAIMER}

This repor was prepared as an account of work sponsored by an agency of the United States Government. Neither the United States Government nor any agency thereof, nor any of their employees, makes any warranty, express or implied, or assumes any legal liability or responsibility for the accuracy, completeness, or usefulness of any information, apparatus, product, or process disclosed, or represents that its use would not infringe privately owned rights. Reference herein to any specific commercial product, process, or service by trade name, trademark, manufacturer, or otherwise does not necessarily constitute or imply its endorsement, recommendation, or favoring by the United States Government or any agency thereof. The views and opinions of authors expressed herein do not necessarily state or reflect those of the United States Government or any agency thereof. 


\title{
The Integration of Surface Micromachined Devices with Optoelectronics: Technology and Applications
}

\author{
M.E. Warren, O. Blum, C.T. Sullivan, R.J. Shul, M.S. Rodgers and J.J. Sniegowski \\ Sandia National Laboratories, MS0603, Albuquerque, NM 87185
}

Sandia National Laboratories has a substantial effort in development of microelectromechanical system (MEMS) technologies. This miniaturization capability can lead to low-cost, small, high-performance "systems-on-a-chip", and have many applications ranging from advanced military systems to large-volume commercial markets like automobiles, if or land-based communications networks and equipment, or commercial electronics. One of the key challenges in realization of the microsystem is integration of several technologies including digital electronics; analog and if electronics, optoelectronics, sensors and actuators, and advanced packaging technologies. In this work we describe efforts in integrating MEMS and optoelectronic or photonic functions and the fabrication constraints on both system components. The MEMS technology used in this work are silicon surface-machined systems fabricated using the SUMMiT (Sandia Ultraplanar Multilevel MEMS Technology) process developed at Sandia. This process includes chemical-mechanical polishing as an intermediate planarization step to allow the use of 4 or 5 levels of polysilicon. ${ }^{1}$

Use of photonic components to activate and power MEMS structures is of interest, because it allows for remote operation of the device. Furthermore, this scheme provides for optical isolation, preventing inadvertent activation of a component and increasing the safety of the system. We have demonstrated powering of electrostatic comb drives using series-connected photo-voltaic (PV) cells to provide the 75 volts needed. The control signals for the drive was provided by the open circuit voltage of the PV cells modulated by a fiber-coupled $850 \mathrm{~nm}$ laser diode. The operation of this device demonstrates feasibility of optically isolating MEMS components and providing drive signals by transmission of optical power.

A second demonstration consisted of a micromachined shutter, interrupting the beam from a Vertical-Cavity Surface-Emitting Laser (VCSEL). The VCSEL was designed to emit at a wavelength of 1.06 microns, ${ }^{2}$ since at that long wavelength the silicon in the MEMS device is more transparent than at shorter wavelengths. Figure 1 shows the VCSEL beam transmitted through the shutter aperture. VCSELs allow for surface-mounting techniques, such as flip-chip bonding, to be used for precision placement of the devices relative to the MEMS parts and the surface-normal emission allows the MEMS components to operate in-plane, not requiring erection of standing structures. The shutter wheel in figure 1 was coated with evaporated gold to increase its opacity with the VCSEL source. This was done after release by a lowtemperature shadow-mask deposition that did not induce strain on the polysilicon wheel. A special hybrid package was assembled that allowed the VCSEL to be located close to the MEMS device and enabled the entire optical beam to pass through the shutter aperture without auxiliary optics. By thus blocking or passing a laser beam, the MEMS shutter can be used to enable transfer of signals or power by optical means.

Continuing work in this area includes improving our post-processing capabilities on MEMS to include metallization to be done prior to release. This will facilitate more advanced packaging options for MEMS components, such as flip-chip bonding as well as adding to the optical performance of mirrors and shutters. This however requires a metallization scheme which will survive the release process or requires protection during the release process. Another approach to allowing light transmission through the MEMS uses through-vias in the silicon substrate. This would allow the use of shorter wavelength VCSELs, including visible wavelengths. Figure 2 shows a via etched through the full thickness of a MEMS die. The edge of a hinged polysilicon mirror is visible through the via. This combination of bulk-micromachining processes with surface-micromachined structures has great potential for integrated microsystems. We are also developing high efficiency diffractive optical elements in polysilicon for incorporation in MEMS-based micro-optical systems. 


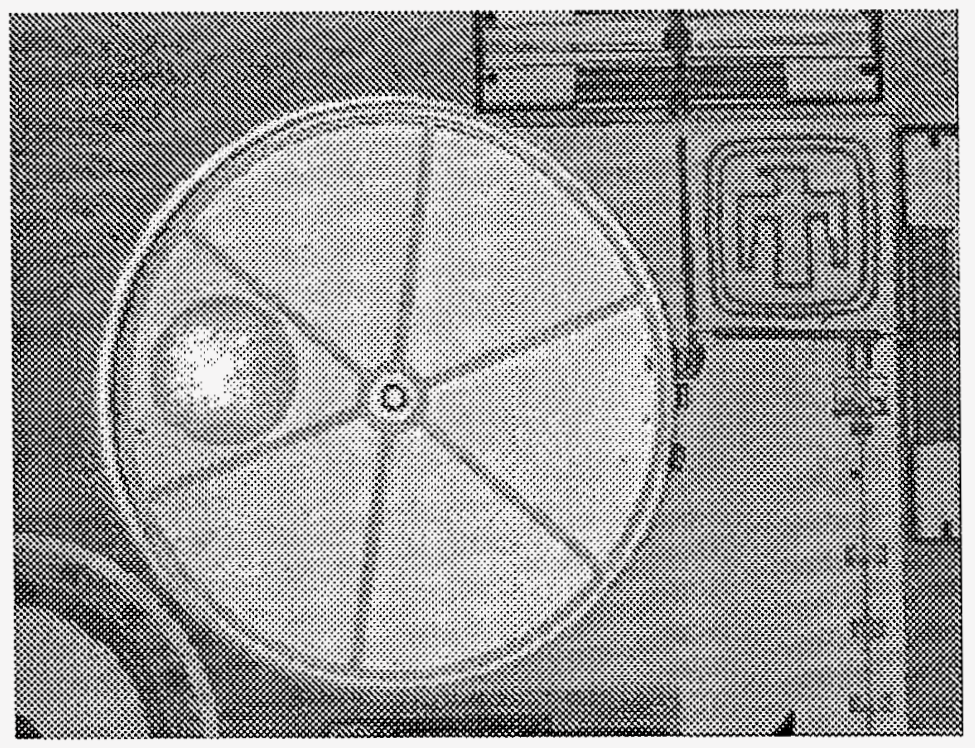

Figure 1. Top view of the metallized shutter and a VCSEL beam visible through a hole in that shutter.

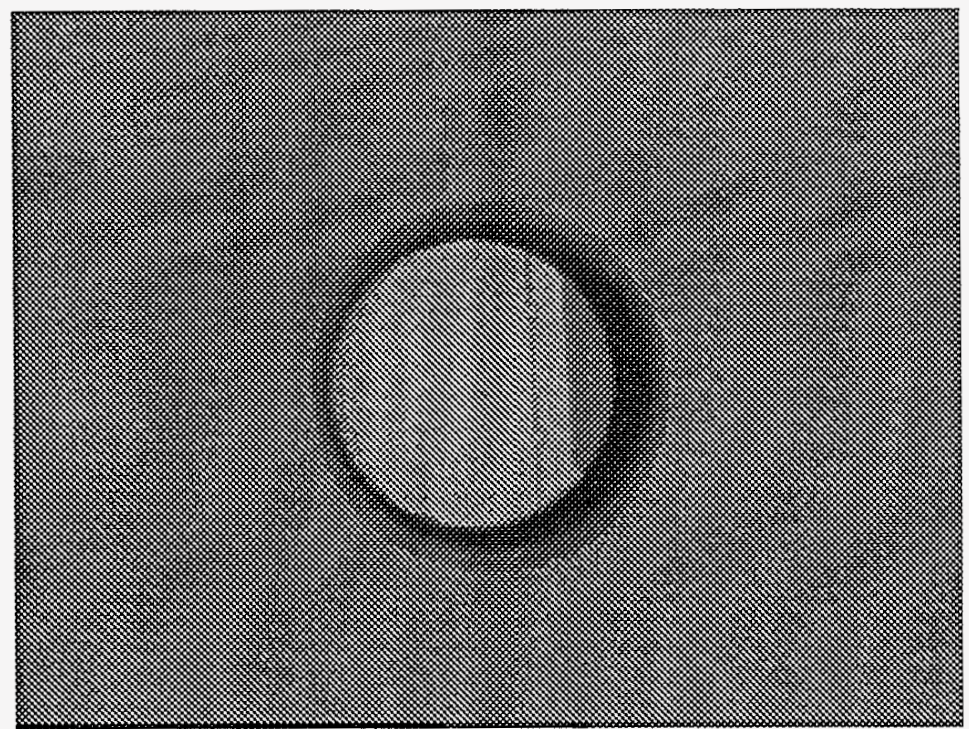

Figure 2. A via hole in the substrate of a MEMS device viewed from the bottom of the substrate. The via whole is through the entire $635 \mathrm{~mm}$ thickness of the substrate, stopping on a dielectric layer beneath the polysilicon MEMS structures. A part of a tilting polysilicon mirror that has not yet been released or erected is visible through the hole.

The authors would like to acknowledge K.D. Choquette and H.Q. Hou for providing the $1.06 \mathrm{~nm}$ VCSEL, R.F. Carson for packaging development, J. Banas and C.G. Willison for processing support. Sandia is a multiprogram laboratory operated by Sandia Corporation, a Lockheed Martin Company, for the United States Department of Energy under contract DE-AC04-94AL85000.

1. C.C. Barron, B.R. Davies, J.J. Sniegowski, M.S. Rodgers, J.H. Comtois and M.A. Michalicek, Proc. SPIE, 3223, pp. 10-16, 1997

2. H.Q. Hou, K.D. Choquette, K.M. Geib, B.E. Hammons, IEEE Photon. Technol. Lett., 9, pp. 10571059, 1997. 


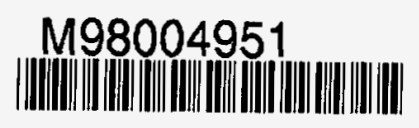

Report Number (14) $\frac{\text { SAND }-98-0913 C}{\text { CONF }-980720--}$

Publ. Date (11)

Sponsor Code (18)

UC Category (19)

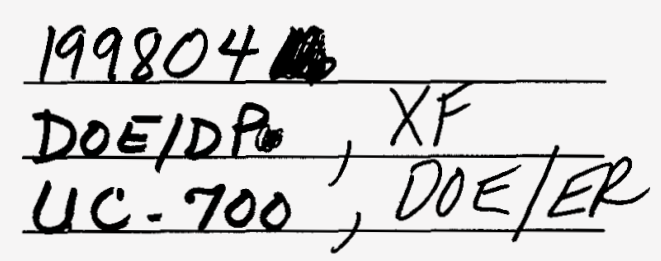

\section{6}

